\title{
Post-Truth Politics: The Effect of Reminders of Political Affiliation on Partisan Op-Ed Viewership
}

\author{
Arron R. Liu ${ }^{1}$ \\ ${ }^{1}$ Saint Francis High School, Mountain View, California, USA \\ Correspondence: Arron R. Liu, Saint Francis High School, Mountain View, California, USA. E-mail: \\ arron.liu.ca@gmail.com
}

Received: November 26, 2018

Accepted: January 7, $2019 \quad$ Online Published: February 28, 2019

doi:10.5539/jpl.v12n1p122

URL: https://doi.org/10.5539/jpl.v12n1p122

\begin{abstract}
Conventional economic theory depicts human-decision making as logical and rational. However, recent research has demonstrated that humans act as an irrational agent more often than not, and will habitually prioritize attitudes, emotions, values, and beliefs over a marginal analysis in their decision-making calculus. As such, individuals will regularly undertake actions in order to avoid conflicts with their beliefs. In particular, information contradicting an individual's beliefs may be avoided to preserve an individual's identity (information avoidance). This paper investigates the phenomena of belief-based utility and information avoidance in the political realm, an area in which the literature regarding the aforementioned theories are relatively sparse. Specifically, we explored whether a reminder of political affiliation could influence subjects to avoid reading op-eds possessing headlines indicative of a position commonly held by an opposing political party. The hypothesis was tested through a survey distributed on Amazon Mechanical Turk, where half the participants received a reminder while the other half did not. The results suggest a statistically significant relationship between reminders and media access behavior - a reminder can have a demonstrable effect on media access behavior by causing individuals to avoid op-eds that advocate for the viewpoints of a conflicting political party. This has multiple implications (increasing political polarization, expanding influence of private interest groups, etc.) regarding media viewership habits for the individual undertaking decisions that may deprive them of useful information.
\end{abstract}

Keywords: reminder, information avoidance, decision making, belief-based utility, political affiliation

\section{Introduction}

For much of the 20th century, normative economic theory considered human decision-making to be prudent and rational. Accordingly, conventional economic models dictated that individuals would seek out information if and only if that information was conducive to their decision-making process. In this framework, the myriad factors that help inform an individual's choice, particularly their beliefs and attitudes, are viewed as responsive to information, all updating optimally in response to the information that he/she receives (Reyna \& Rivers, 2008). However, this model has been shown to be unsuitable for practical usage. Indeed, a majority of people hold their personal beliefs extremely dearly and will defend their beliefs when they perceive them being threatened. In this way, initial beliefs held by individuals become increasingly resistant to change. Belief-based utility, when considered in an individual's decision-making calculus, can offer explanations for inconsistent information seeking and information avoiding behavior.

Values and beliefs often are not specific to an individual. Instead, certain types of values have been found to be correlated. For example, those who cherish "achievement" are also inclined to value "power" and "hedonism" (Schwartz 1994). Furthermore, people often derive their personal beliefs and values not from their own needs, but from social interaction and in cases where promoting group harmony is beneficial. Political ideologies, as socially constructed identities, supply values and beliefs for multitudes of voters. In recent years, the phenomenon of political polarization has caused many distinct political identities associated with American political parties such as Republican and Democrat to become increasingly divided and hostile to opposing parties. Personal identity plays a significant role in decision making and economic outcomes. For example, when incorporating individual identities into conventional economic scenarios (gender discrimination in the workplace, household division of labor, etc.), identity has been shown to play an important role in shifting individual interactions and altering the outcomes predicted by normative economic analyses (Akerlof and Kranton 2000). Because beliefs are connected 
to one's sense of identity, any perceived challenge to an individual's beliefs often is strongly rejected.

In this paper, the theories of belief-based utility and information avoidance are explored in the context of politics. The literature substantiating the phenomena of information avoidance is relatively lacking in regard to research performed in the political perspective. Individuals on all sides of the political spectrum may avoid information written from an opposing point of view, even when it offers them useful information that benefits their decision-making (i.e. voting) calculus. Moreover, people may be more inclined to avoid information contradicting their beliefs when their beliefs are made more conspicuous to themselves (such as through an electronic pop-up). This research investigates the effect of personal reminders of political affiliation on an individual's media viewership decisions. The hypothesis proposed that a reminder of an individual's political beliefs would cause that specific individual to increasingly avoid reading op-eds written by members of the rival political party and instead favor reading op-eds holding common attitudes held by their own political party.

\subsection{Literature Review}

\subsubsection{Contemporary Beliefs in Economics}

Traditionally, economists have viewed humans as rational decision-makers bounded by logic and judgement (Reyna \& Rivers, 2008). Indeed, a large body of work supporting rational decision making have been composed by economists and psychologists, all focused on the assumed premise that the human psyches have been inducing individuals to maximize expected utility in every choice they make (Reina \& Rivers, 2008). In the lens of this expectancy-value approach, individuals undertake behaviors if and only if that behavior will optimize their benefit and minimize their loss - in other words, the best possible decision they could make under the circumstances. More specifically, if an individual has the choice between paying to watch a movie or going to a restaurant, this kind of rational framework predicts that the individual will carefully weigh all the factors (price, personal preferences, etc.) and will choose either the movie or the restaurant based on whatever option produces the most desired outcome. Thus, at its core, the customary theory has relied on an outcome-based predictive approach. However, expectancy-value theory also has its limitations. In this model, humans are assumed to be wholly rational, making decisions according to a theoretical framework, when in fact we are often irrational. Most importantly, an outcome-based decision-making theory fails to take into account other crucial factors that are inputs in a human's decision-making calculus. As imperfect-rational actors, consumers are prone to a plethora of fallacies and biases that drastically affect their decision-making processes. A classic example is the sunk cost effect. According to normative economic theory, historical costs should be irrelevant in a purchasing decision. However, the theory is proven inconsistent with reality, with a plethora of cases demonstrating otherwise. For instance, consider the scenario of a man that pays a $\$ 300$ yearly membership fee to join a tennis club who subsequently develops a tennis elbow after two weeks of playing (Thaler 1980). Contrary to the normative consumer choice model, the man will continue playing even while afflicted with his injury; he justifies increasing the risk for further injury and pain by claiming that he does not want to "waste" the $\$ 300$. Other significant biases affecting human decision-making include identity-relevant beliefs, social circumstances, and personal values.

\subsubsection{The Relationship between Identity and Beliefs}

Decision-making behavior is crucial to developing a strong social identity. After all, the social categorization that results from separate social identities can only exist through a multitude of decisions made by different populations of people. Rational choice theory holds that actions are rational if and only if the actions undertaken are subject to an optimization process that includes considering an individual's personal beliefs, desires, and available information against the methods and result of a choice (Hedstrom 2005, 2006). As such, beliefs and desires can be considered fundamental aspects in the decision-making process. Individuals weigh both their desires and beliefs either against or with each other in order to make the choice that is most prudent considering their circumstances. Thus, it can be suggested that social identity consists of either a set of desires or a set of beliefs. Which set acts as a more accurate definition? Fernando Aguiar and Andrés de Francisco argue that social identity is more akin to a web of beliefs about oneself, due to the emotional component present in identity. In multitudes of studies conducted in psychology and economics, identity and beliefs have been shown time and time again to be intrinsically linked.

\subsubsection{The Phenomenon of Information Avoidance}

In regard to information, the implication caused by rational choice theory is that valid information should never be consciously disregarded, except for situations in which obliviousness causes a net benefit. One of the major theories opposing the outcome-based approach, and the one that will be discussed in this paper, is that of belief-based utility. In this framework, individuals are viewed as placing great emphasis (not just a belief in the outcome, but personal) in their personal beliefs when making decisions. Consider a continuation of the previous 
movie/restaurant scenario proposed in Part A. Even if an individual believes that he/she will prefer to spend his/her money on a delicious dinner, he/she may choose to watch the movie instead because he/she does not want to be the only person not to have seen a popular movie. In this case, the individual's belief that others have all chosen to watch the movie actually manipulates his/her decision-making process. Beliefs have thus entered the utility function, opening up myriad possibilities. An interesting phenomenon proposed by this belief-based model is that individuals will take great measures to avoid any disagreements with their beliefs, producing this pattern of information avoidance. Information avoidance has been proven to be extremely common (Golman et al., 17). For instance, individuals at risk for medical conditions may avoid going to the hospital for a medical examination, even when this information would benefit them greatly. The consequences of information avoidance are dire: it withholds potentially beneficial advice for both decision-making and behavior, and even promotes political polarization and media bias by removing common ground between political parties (Golman et al., 17). Given this, both Republicans and Democrats are expected to avoid viewing op-eds written by other political parties if there is a chance that the op-eds contain information contrary to their beliefs (hypothesis).

\subsubsection{Information Avoidance in Regard to Political Affiliations}

In the political context, there has been a relatively small body of work composed regarding information avoidance. Previous research suggests that political preferences can indeed influence the media that individuals view. In a 2008 study conducted by Shanto Iyengar and Kyu Han, the demand for various news outlets changed based on how the news outlets' political stances agreed or disagreed with that of consumers. Republicans preferred to read news reports from Fox News and to avoid news from CNN and NPR. On the other hand, Democrats consumed media from CNN and NPR, but avoided Fox News. This suggests that a reminder of political belief should possess the ability to change how individuals choose to view political information. Through the reminder, the individual's personal political affiliation (and thus identity) become more salient to themselves. This paper explores the hypothesis that individuals will actively avoid political information that threatens their personal identity and beliefs.

\section{Method}

Hypothesis:

Reminders about a person's affiliation with a political party make that individual less likely to read an op-ed written by a member of the opposing political party.

\subsection{Overview}

The hypothesis was tested through a Qualtrics survey distributed on Amazon Mechanical Turk over a period of one month. There were two conditions established for the experiment: half of the survey respondents received a reminder while half did not. Data was gathered on 1) individual's self-reported political affiliation (leaning more to either Republicans or Democrats), 2) whether individuals self-identified as generally information seeking or information avoiding about political opinions, 3 ) which of four available op-eds they chose to read (with headlines proclaiming support for either traditionally Republican or traditionally Democratic viewpoints), and 4) personal characteristics (age, gender, income, etc.).

\subsection{Participants}

Using Amazon Mechanical Turk, one hundred and eighty-two participants (122 males/60 females; median age range $=28-34$ ) were recruited during July 2018 to take part in this study. Recruitment for the study was conducted over the period of two weeks. The participants were required to be adult U.S. citizens currently residing in the United States. A majority of participants in the study were male, Christian, and had completed at least a 4-year degree. Restrictions on demographic characteristics (excluding nationality and age) were not implemented when recruiting research subjects. The participants participated in a "political research" study that required them to "answer several questions regarding their political views" and were paid \$1.50 USD. There was no penalty for failing to complete the study, and participants could exit the survey at any time.

\subsection{Procedure}

The study was completed online (on mobile device or personal computer) by all participants. Participants were first queried on their political affiliations. More specifically, participants were asked "As of today, do you lean more to the Republican Party or more to the Democratic Party?". After answering, respondents would be randomly assigned to receive or not receive a reminder of their political affiliations.

The "reminder" asked participants to briefly explain several reasons behind why they identify more of either a Republican or Democrat, based on their response to the previous question. Next, participants were given a list of 
four op-eds and chose one to read. All op-eds were about the topic of affirmative action, with two op-eds being written from a Republican viewpoint and two op-eds being written from a Democratic viewpoint. The titles of the articles were shown to the reader as follows:

1) Asian Americans need to wise up and end our blind loyalty to the Democratic Party

2) Does the nation still need affirmative action?

3) Let's Agree - Racial Affirmative Action Failed

4) Racial Justice Demands Affirmative Action

Articles 1 and 3 were written from the Republican position, while articles 2 and 4 were written from the Democratic perspective. Each article's political affiliation was implied and could be comfortably discerned through the title of the article.

After reading the article, participants were queried on three reading comprehension questions. Subsequently, they were asked whether their opinions on affirmative action had changed (more supportive or more against) from reading the article.

Afterwards, a five-point Likert scale was used to determine whether respondents were generally information seeking or information avoiding in the context of political media consumption habits. Participants were asked to rate statements such as "I plan to read more op-eds that align with my political view in the future" and "I ignore political information that contradicts with my own expectations" on whether they agreed, disagreed, or were impartial. In measuring the extent to which they agreed or disagreed with the statements, the options of "strongly agree", "somewhat agree", "strongly disagree", and "somewhat disagree" were present on the scale. At the end, questions regarding personal characteristics were asked. These questions were chosen to be placed at the end of the survey to avoid any possibility of priming bias.

After sorting and cleaning the collected data, each survey response was coded using a binary outcome ( 0 if a participant did not read an article they expected to agree with; 1 if they did) to determine the effect of the reminder on information avoidance. A mean rating (from 0-1) was calculated for each group based on whether they read an article they were expected to agree with (e.g. Democrat reading an article written from the Democratic viewpoint); the rating represented the frequency of those who chose the article that they were predicted to read. The means were compared using two-tailed hypothesis tests.

\section{Results}

Out of around 300 respondents recruited on Amazon Mechanical Turk, 118 were excluded because of survey incompletion or incorrect answers to reading comprehension questions. As such, around $61 \%$ the sample recruited successfully completed the study. In regard to political affiliations, $83(46 \%)$ respondents identified themselves as Republicans, while 99 (54\%) respondents identified as Democrats.

The hypothesis proposed that a reminder of an individual's political beliefs would cause that specific individual to increasingly avoid reading op-eds written by members of the opposing political party.

The mean for Condition 1 (those having received the reminder) was 49\%, while the mean for Condition 0 was $64 \%$. The $\mathrm{p}$ value calculated for the between the two conditions was around $4.5 \%$. Thus, the data suggested a statistically significant relationship between a reminder of political affiliation and the willingness to avoid reading op-eds of an opposing ideological perspective. The relationship between receiving a reminder of political affiliation and avoiding reading op-eds written by members of the opposing political party was not rejected. The null hypothesis was rejected.

We characterized 83 subjects as information seeking, and 76 subjects as information avoiding. The participants were categorized by their respective responses to the Likert scale; those that chose "strongly" or "somewhat" agree/ "strongly" or "somewhat" disagree to the information seeking or information avoiding assigned statements were characterized as information seeking or information avoiding. The remainder of the subjects were either impartial to the statements or were simultaneously information seeking and information avoiding.

Another analysis was completed to confirm whether political polarization was occurring - would Democrats and Republicans increasingly choose articles written by the members of the political party they were affiliated with to read, even without the reminder? A z-test was undertaken with the mean in Condition 0 to determine if the results were statistically different from $50 \%$. The z-test demonstrated that political polarization was statistically evident, with a z-test value of $0.3 \%$.

Subsequent subgroup analyses (for males, females, Republicans, and Democrats) demonstrate a negligible and 
statistically insignificant difference $(p>0.05)$ between the means of these respective subgroups compared to the mean rating of the entire sample.

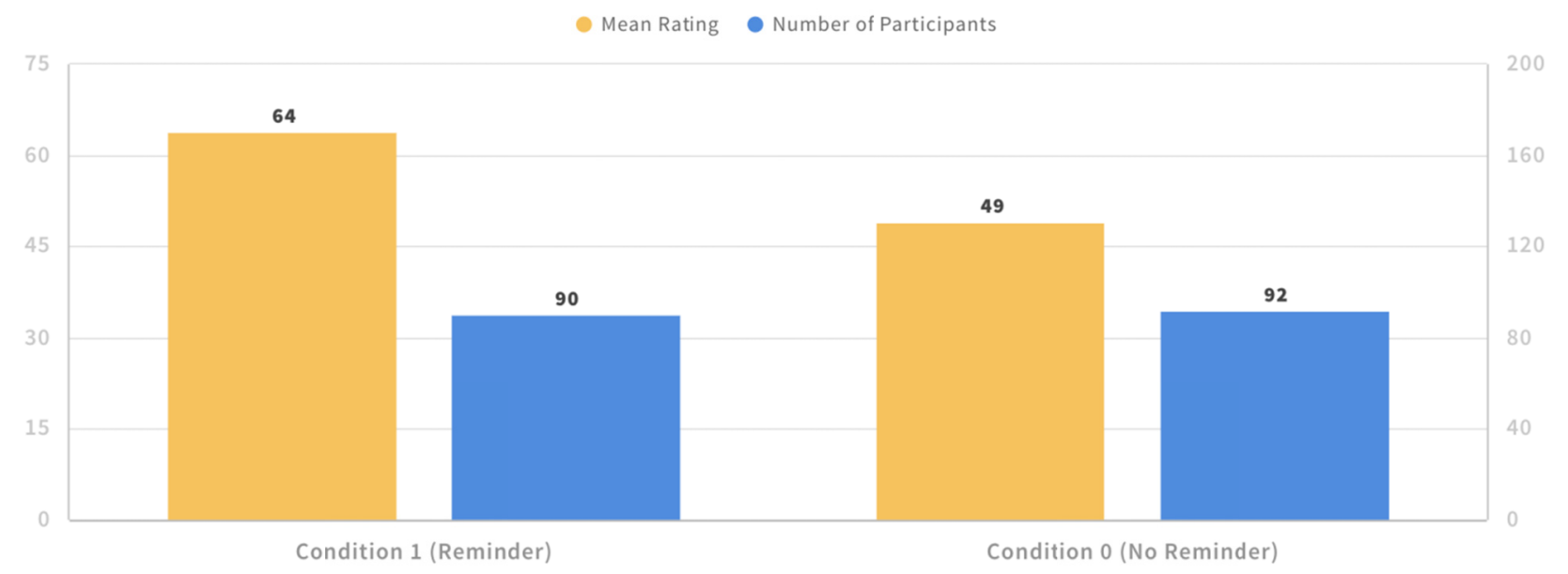

Figure 1. Mean rating and number of participants in each condition

\section{Discussion}

In this paper, the hypothesis of whether a reminder of an individual's political beliefs would cause that specific individual to avoid reading op-eds written by members of the opposing political party was explored and empirically tested. The analyses of the collected data demonstrated that there was significant evidence to support a causal relationship between reminding an individual of their political ideology and that same individual avoiding reading articles written by people possessing opposing political affiliations.

\subsection{Reminders Produce a Significant Effect}

The analyzed data supported the hypothesis: a statistical difference was demonstrable between the two conditions. Thus, the null hypothesis was rejected. Moreover, the population was split between information seeking and information avoiding individuals. Both confirmation bias and the information avoidance were illustrated to have significant influence on individual decision-making behavior. The research ultimately suggests that reminders can play a role in decision-making and/or manipulate the types of political information an individual chooses to view. By causing an individual's beliefs and identity to become more salient to themselves, the same individual may be more inclined to avoid information that disagrees with or undermines his/her beliefs. At the same time, that individual may also be more inclined to access information that supports or strengthens his/her beliefs.

\subsection{Limitations}

The results of the study were restricted by its limited sample size. While 182 participants are adequate, more sizable cohorts could be tested to more tangibly determine the effects of the reminder. In the future, larger sample sizes could be used to substantiate with greater accuracy and expand on the results obtained in this study. The lack of a diverse sample population was also a significant limitation of the study. Indeed, the achieved sample differed in a variety of ways from the target population (eligible U.S. voters). The effects of selection bias may also have distorted the statistical analyses performed in this study. The participants themselves were self-selected through Amazon Mechanical Turk, and as such only representative of a subset of the target population (U.S. voters). Additionally, the majority of research participants were male, and clear socio-political differences were present between participants in the study (religion, annual income, etc.). Another limitation of this research lies in the method used to judge whether subjects are truly information-seeking or information-avoiding. The implementation of a single Likert scale leads to some uncertainty about the phenomena at play in determining the choice of op-ed. Is the respondent actively avoiding information that may contradict their beliefs, or is he/she being influenced by confirmation bias and information-seeking behavior to strengthen his/her beliefs? The Likert scale is insufficient in generating a cogent conclusion to this question. Finally, the topic of articles chosen may have had an impact on individual decision-making. Affirmative action is a controversial issue that many people have idiosyncratic views about, with many Democrats supporting the Republican stance on affirmative action. In the future, a different, more divisive and polarizing op-ed topic could be used to greater illustrate the distinction between the two conditions. 


\section{Conclusion}

This research study aimed to explore the effect of reminders of political affiliation on an individual's political media viewing habits. The analyses suggest that there is a causal relationship between the two; the hypothesis was supported with statistically significant evidence. Reminders of political affiliation have a great effect on an individual's political media viewing habits, and also illuminate deep implications in the field of politics.

In contemporary American politics, a plethora of severe issues permeate deeply throughout the electoral system. Low voter turnout, the possibility of manipulated elections, and political polarization all are subjects functioning to undermine the stability of American democracy. In particular, the rising political polarization and growing Republican-Democrat divide has been increasingly effective in minimizing the influence of substantive information. Moreover, political polarization has also caused the rise in credibility/confidence of unfounded partisan opinions (Druckman, Peterson, \& Slothuus, 2013). Indeed, political extremists and single-issue advocates have become progressively more influential in manipulating public opinion (Baldassarri \& Gelman, 2008). The possibility of private interest groups manipulating public opinion on a national scale is a threat that continuously degrades the integrity of the American political process. With influencing political opinion shown to be possible with a single reminder, governments aiming to preserve an egalitarian electoral process may need to enact cautionary measures in order to ensure the stability of a democratic system. While the U.S. government has taken steps to prevent foreign interference in the electoral process, just as much attention needs to be designated towards nationally-based political extremist/third-party interest groups. The results also possess great social and pedagogical relevance in the contemporary zeitgeist. In the age of "fake news", understanding how individuals choose their media channels is of paramount importance for mitigating the spread of false information, promoting critical thinking abilities, and avoiding further political polarization.

\section{References}

Aguiar, F., \& de Francisco, A. (2009). Rational Choice, Social Identity, and Beliefs about Oneself. Philosophy of the Social Sciences, 39(4), 547-571. https://doi.org/10.1177/0048393109333631

Akerlof, G. A., \& Kranton, R. E. (2000). Economics and Identity. The Quarterly Journal of Economics, 115(3), 715-753. https://doi.org/10.1162/003355300554881

Baldassarri, D., \& Gelman, A. (2008). Partisans without Constraint: Political Polarization and Trends in American Public Opinion. American Journal of Sociology, 114(2), 408-446. http://dx.doi.org/10.2139/ssrn.1010098

Druckman, J., Peterson, E., \& Slothuus, R. (2013). How Elite Partisan Polarization Affects Public Opinion Formation. American Political Science Review, 107(1), 57-79. https://doi.org/10.1017/S0003055412000500

Iyengar, S., \& Hahn, K. S. (2009). Red Media, Blue Media: Evidence of Ideological Selectivity in Media Use, Journal of Communication, 59(1), 19-39. https://doi.org/10.1111/j.1460-2466.2008.01402.x

Reyna, V. F., \& Rivers, S. E. (2008). Current Theories of Risk and Rational Decision Making. Developmental review: $D R, 28(1), 1-11$. https://doi.org/10.1016/j.dr.2008.01.002

Schwartz, S. H. (1994), Are There Universal Aspects in the Structure and Contents of Human Values? Journal of Social Issues, 50, 19-45. https://doi.org/10.1111/j.1540-4560.1994.tb01196.x

Smith, J., Bitsura-Meszaros, K., \& Keane, R. (2015). Differences between conservatives and liberals in information seeking behavior and perceived risks associated with climate-driven changes to local forest conditions. Weather, Climate, and Society, 8. http://dx.doi.org/10.1175/WCAS-D-15-0046.1

Thaler, R. (1980). Toward a positive theory of consumer choice. Journal of Economic Behavior \& Organization, l(1), 39-60. https://doi.org/10.1016/0167-2681(80)90051-7

\section{Copyrights}

Copyright for this article is retained by the author(s), with first publication rights granted to the journal.

This is an open-access article distributed under the terms and conditions of the Creative Commons Attribution license (http://creativecommons.org/licenses/by/4.0/). 